NBER WORKING PAPER SERIES

\title{
THE EFFECTS OF CALIFORNIA'S PAID FAMILY LEAVE PROGRAM ON MOTHERS' LEAVE-TAKING AND SUBSEQUENT LABOR MARKET OUTCOMES
}

\author{
Maya Rossin-Slater \\ Christopher J. Ruhm \\ Jane Waldfogel \\ Working Paper 17715 \\ http://www.nber.org/papers/w17715
}

\author{
NATIONAL BUREAU OF ECONOMIC RESEARCH \\ 1050 Massachusetts Avenue \\ Cambridge, MA 02138 \\ December 2011
}

The authors gratefully acknowledge funding support from the Eunice Kennedy Shriver National Institute of Child Health and Human Development (NICHD) through R01HD047215 as well as R24HD058486. The content is solely the responsibility of the authors and does not necessarily represent the official views of NICHD or the National Institutes of Health. The views expressed herein are those of the authors and do not necessarily reflect the views of the National Bureau of Economic Research.

NBER working papers are circulated for discussion and comment purposes. They have not been peerreviewed or been subject to the review by the NBER Board of Directors that accompanies official NBER publications.

(C) 2011 by Maya Rossin-Slater, Christopher J. Ruhm, and Jane Waldfogel. All rights reserved. Short sections of text, not to exceed two paragraphs, may be quoted without explicit permission provided that full credit, including $(\mathcal{C}$ notice, is given to the source. 
The Effects of California's Paid Family Leave Program on Mothers' Leave-Taking and Subsequent Labor Market Outcomes

Maya Rossin-Slater, Christopher J. Ruhm, and Jane Waldfogel

NBER Working Paper No. 17715

December 2011

JEL No. H75,J13,J18,J2

\begin{abstract}
This analysis uses March Current Population Survey data from 1999-2010 and a differences-in-differences approach to examine how California's first in the nation paid family leave (PFL) program affected leave-taking by mothers following childbirth, as well as subsequent labor market outcomes. We obtain robust evidence that the California program more than doubled the overall use of maternity leave, increasing it from around three to six or seven weeks for the typical new mother - with particularly large growth for less advantaged groups. We also provide suggestive evidence that PFL increased the usual weekly work hours of employed mothers of one-to-three year-old children by 6 to $9 \%$ and that their wage incomes may have risen by a similar amount.
\end{abstract}

Maya Rossin-Slater

Columbia University, Department of Economics

1022 International Affairs Building

420 West 118th Street

New York City, NY 10027

mr2856@columbia.edu

Christopher J. Ruhm

Frank Batten School of

Leadership and Public Policy

University of Virginia

235 McCormick Rd.

P.O. Box 400893

Charlottesville, VA 22904-40893

and NBER

ruhm@virginia.edu
Jane Waldfogel

Columbia University

School of Social Work

1255 Amsterdam Avenue

New York, NY 10027

jw205@columbia.edu 
The United States is the only advanced industrialized country without a national law providing new mothers (and often fathers) with entitlements to paid family leave (PFL). However, three states have implemented paid leave programs, the first of these being California, where PFL took effect in 2004. We study how California's program has affected leave-taking by mothers following childbirth, and the extent to which these effects differ across population subgroups. We are particularly interested in learning whether PFL has reduced previous disparities in leave-taking, whereby advantaged mothers have been much more likely to use leave than their less advantaged counterparts. We also provide an initial investigation of the medium-term impacts on mothers' labor market outcomes: employment, work hours, and wage income.

The analysis uses March Current Population Survey data from 1999-2010 and a differences-in-differences (DD) approach to compare pre- versus post-program implementation experiences of mothers with infants or young children - the treatment groups - to control groups alternatively consisting of women with older children, childless women, men with non-infant children, or new mothers in other states. ${ }^{1}$ We obtain robust evidence that the California program increased leave-taking, more than doubling overall maternity leave use - increasing it from around 3 to 6 or 7 weeks - with particularly large growth for less advantaged mothers (those who are less educated, unmarried, or nonwhite) who had relatively low levels of baseline use. This contrasts starkly with the results for other state family leave laws (most of which extend rights to unpaid leave beyond those in the FMLA), where the estimated effects are much larger for college-educated and married women than for less advantaged counterparts (Han, Ruhm and Waldfogel, 2009). The exploration of effects on medium-term labor market outcomes provides

\footnotetext{
${ }^{1}$ We considered men with infant children as a treatment group, since such fathers are covered under PFL, but did not find consistent evidence of effects on leave-taking. This may have occurred because low rates of paternity leave use imply that we did not have the power to detect statistically significant effects.
} 
more equivocal results, but with evidence that paid family leave led to 6 to $9 \%$ increases in usual weekly work hours for employed mothers, and that their wage incomes may have risen by a similar amount.

\section{Background}

All industrialized nations, other than the United States, grant parents the right to take time off work with pay following the birth or adoption of a child (Earle, Mokomane, and Heymann, 2011). ${ }^{2}$ In European countries, a period of at least 14 to 20 weeks of maternity leave is provided, with 70 to $100 \%$ of wages replaced. ${ }^{3}$ Subsequent to this, some form of paid parental leave (available to both mothers and fathers although a portion is sometimes reserved for one parent) is typically supplied. The duration of the job-protection and leave payment differs substantially across nations, but the total duration of paid leave exceeds nine months in the majority of them. Our neighbor to the North, Canada, currently provides at least one year of paid leave, with around 55\% of wages replaced, up to a ceiling (Doucet, Lero, and Tremblay, 2011). ${ }^{4}$

Until enactment of the Family and Medical Leave Act (FMLA) in 1993, the United States did not even provide rights to unpaid leave. Under the FMLA, firms employing at least 50 persons within 75 miles of the work site are required to offer eligible workers 12 weeks of jobprotected but unpaid time off work to care for newborn or newly adopted children (as well as for other reasons such as serious medical problems). ${ }^{5}$ However, the firm size and work history requirements (the individual must have worked for the firm 1250 hours during the previous 12 months) imply that only around half of employees are eligible for FMLA leave.

\footnotetext{
${ }^{2}$ Australia, long the other exception, began providing 18 weeks of paid leave in 2011. (For details, see: http://www.familyassist.gov.au/payments/family-assistance-payments/paid-parental-leave-scheme/.)

${ }^{3}$ Unless otherwise noted, the material in this section is drawn from a more extensive discussion in Ruhm (2011).

${ }^{4}$ The leave period is 70 weeks in Quebec.

${ }^{5}$ Firms are required to continue health insurance during the leave period. See U.S. Department of Labor (2010) for further information on provisions of the FMLA.
} 
A number of states extend the FMLA by providing rights to unpaid leave to additional employees or for longer periods of time. In addition, pregnant women and new mothers in the five states (California, Hawaii, New Jersey, New York and Rhode Island) offering temporary disability insurance (TDI) can take some time off work with pay - usually for around six weeks at one-half to two-thirds earnings - for pregnancy related short-term "disabilities", although at least some of this leave usually occurs before the birth.

We examine consequences of California's first in the nation explicit paid family leave program, which took effect in July 2004. California PFL offers six weeks of partially paid leave to bond with a newborn or a recently placed foster or adoptive child, or for other reasons (such as to care for seriously ill relatives). ${ }^{6}$ Almost all private sector workers are eligible (unlike the FMLA, with its employer-size and work history requirements) and wage replacement is $55 \%$ up to a ceiling based on the state's average weekly wage. PFL has many elements in common with the California TDI program: job protection is not provided during the leave, unless the individual is eligible for and simultaneously uses FMLA leave; financing is through payroll taxes levied on employees (without employer payments); and the two programs are closely coordinated, so that PFL can start immediately after TDI leave ends. One difference is that PFL applies equally to mothers and fathers.

Studying the effects of the California paid leave program is interesting in its own right and because the results may be informative for understanding the potential effects of similar programs enacted in other states or nationally. These possibilities are salient. In 2009, New Jersey implemented a paid parental leave program that is similar, in many ways, to that in

\footnotetext{
${ }^{6}$ The discussion in this paragraph and the next is based on information provided in Fass (2009).
} 
California. ${ }^{7}$ Washington State also passed a more limited paid leave program, originally scheduled to begin in 2009, but delayed until at least 2012 due to budgetary pressures. ${ }^{8}$ The immediate prospects for a national PFL program are less favorable but substantial advocacy and limited legislative efforts have been undertaken. ${ }^{9}$

Prior research provides some guidance as to how unpaid leave rights in the U.S. affect women's leave usage and subsequent employment. Mothers giving birth post-FMLA in states that did not previously have maternity leave statutes are more likely to use maternity leave and take more time off work than those giving birth pre-FMLA (Waldfogel, 1999; Han et al., 2009). State unpaid leave statutes are also associated with increased leave-taking although the effects are small and the estimates are less consistent (Klerman and Leibowitz, 1997; Han and Waldfogel, 2003; Washbrook, Ruhm, Waldfogel, and Han, 2011). The effects of unpaid leave policies are largest for relatively advantaged women, who are more likely to be eligible for leave under such policies and able to afford unpaid time off work. ${ }^{10}$

The effects of paid leave, however, could be quite different. In particular, disadvantaged mothers might be more able to use paid than unpaid time off work, potentially reducing disparities in leave-taking. Evidence from other countries' paid leave expansions supports this possibility. Studies of Europe and Canada consistently show that take-up of paid leave is very high, often close to universal (see e.g. Rønsen and Sundström, 2002; Baker and Milligan, 2008; Burgess et al., 2008; Dustmann and Schonberg, 2008; Carneiro, Loken, and Salvanes, 2010; Liu

\footnotetext{
${ }^{7}$ As in California, the duration of leave is 6 weeks, financing occurs through an employee-only payroll tax and the program builds upon the state's existing TDI program. Wage replacement rates are higher in New Jersey than California (66\% versus 55\%) but the maximum benefit is lower (\$546 in 2009 versus \$959 in California).

${ }^{8}$ Washington was scheduled to offer a flat benefit of $\$ 250$ for five weeks, with job-protection provided to persons meeting the same work history requirements as in the FMLA.

${ }^{9}$ For example, in 2007, Senators Dodd and Stevens proposed a Family Leave Insurance Act that would have provided 8 weeks of paid benefits for time off work for the same reasons as in the FMLA, financed by employee and employer premiums (see http://wfnetwork.bc.edu/encyclopedia entry.php?id=16912\&area=All for further details).

${ }^{10}$ For example, Han et al. (2009) find that the positive effects on leave-taking are confined to college-educated or married mothers, with no significant effects for those who are unmarried or have less education.
} 
and Skans, 2010; Rasmussen, 2010). Second, when paid leave has been introduced to replace a former system of at least partially unpaid leave, effects on leave-taking have been largest among disadvantaged women least likely to have used unpaid leave (see, for example, evidence from Norway in Carneiro et al., 2010). The effects of maternity leave rights on employment are theoretically ambiguous, since longer leave periods might cause women to stay on leave longer, or might boost job-holding because mothers no longer need to quit jobs to obtain time off work (Klerman and Leibowitz, 1997); however, empirical studies suggest that the latter effect dominates, particularly when the period of leave provided is not excessively long (see e.g. Gregg, Domenech, and Waldfogel, 2007). With regard to longer-run labor market effects, comparative studies find that extended paid leave entitlements are associated with modestly higher female employment rates, although with some concern that excessively long leave periods (periods well in excess of a year) could have detrimental effects (see e.g. Ruhm, 1998; Jaumotte, 2004; Pettit and Hook, 2005).

On the other hand, the impact of the California program might differ from those studied above, because wage replacement rates are considerably lower than in most European countries (but not Canada). Moreover, Appelbaum and Milkman (2011) provide evidence that public awareness of the program remains limited, even six years after implementation, and with fear of negative employment consequences for using it being cited by many individuals who know about the program but do not apply for benefits. Even if the program does increase leave-taking, it is not obvious for which groups the effects will be strongest.

\section{Data}

We use 1999-2010 data from the March Current Population Survey (CPS) Annual Demographic Supplement, accessed via the Integrated Public Use Microdata Series (IPUMS) 
database. The CPS data are useful because they provide information on leave-taking and labor market outcomes for a large and nationally-representative sample. Questions about the use of maternity and paternity leave are asked directly of individuals reporting being with a job but absent from work during the reference week (the week immediately before the survey). Limitations include the lack of precise information on child birth dates and on women's employment status during pregnancy. To our knowledge, no other large and representative data sets combine this information with that on leave use.

When analyzing effects on leave-taking, we limit the sample to persons employed (reporting any usual work hours) in the prior year. The treatment group consists of women residing in California with an infant (less than 1 year old at the survey date) in the household who reported working any usual hours in the previous year $(\mathrm{N}=1,422)$. While this definition captures most women eligible for PFL, we would ideally like to restrict the analysis to those working throughout most of their pregnancy (which our data will not permit). Most resulting classification errors are likely to be minor. For example, a woman with an 11-month-old child surveyed in March 2007 most likely became pregnant during the last quarter of 2005 . If she worked at the end of 2005, but not during 2006, we would exclude her from the treatment group, even though she had some pregnancy employment. That said, it is unlikely that she would have been eligible for PFL, given that she stopped working several months before childbirth. Potentially more problematic, we will misclassify into the treatment group women who did not work during pregnancy but began to do so after childbirth but during the reference year. For example, we would erroneously place into the treatment group a mother whose child was 11- 
months old in March 2007, who gave birth in April 2006, and only worked during that year in the period after childbirth. ${ }^{11}$

If the measurement error described above is random, it would be likely to attenuate the estimated effects. Potentially more serious, however, is that bias may be introduced if there is selection into the treatment group as a result of PFL. For example, if it increases post-birth employment, then the potential misclassification of women who only worked after childbirth into the treatment group could be more problematic. To address this issue, we also estimated regressions that included all women with youngest children aged $<1$ year in California in the treatment group, regardless of last year's reported employment. These regressions represent intent-to-treat (ITT) analyses rather than the treatment-on-the-treated (TOT) analyses that we emphasize below. However, the ITT results are very similar to the presented TOT estimates, when scaled by the pre-treatment fraction of treatment women working during the last year, suggesting that this source of selection bias is unlikely to be serious. ${ }^{12}$

Our primary control group consists of women residing in California with a youngest child aged 5-17 years at the time of the survey, and who reported working any usual hours in the previous year $(\mathrm{N}=13,555)$. The key assumption is that mothers with older children (sometimes referred to as control group 1 below) would have similar employment trends, in the absence of the treatment, to women with infants. Ideally, we might have used mothers with toddlers (i.e. 1to 3-year-olds) as controls, assuming that their work behavior would be even more similar to the treatment group. However, this might be problematic if such mothers are pregnant or planning to become pregnant in the near future, so that their labor market behavior might be affected by the

\footnotetext{
${ }^{11}$ Such misclassifications are likely to be relatively rare, since relatively few mothers not working during pregnancy are employed shortly after childbirth. For example, Han, Ruhm, Waldfogel, and Washbrook (2008) present evidence that only around a quarter of mothers giving birth in 2001, and not employed at birth, were working 4 months later. ${ }^{12}$ These results are available upon request.
} 
presence of paid family leave. As an alternative, we estimated models with varying minimum child threshold ages (between two and eight years old) for inclusion of mothers into the control group. The results are not sensitive to this choice as briefly discussed below.

The assumption of a common trend between our treatment and primary control groups might be violated (e.g. if macroeconomic conditions differentially affect the two groups). Although we cannot completely eliminate the potential bias this might introduce, we address this possibility by testing the robustness of the results to the choice of several alternative comparison groups. These include: women residing in California with no children $(\mathrm{N}=22,091)$; men residing in California with no children $<1$ year old $(\mathrm{N}=53,584)$; women with infants residing in one of the next three largest states - Florida, New York, and Texas $(\mathrm{N}=2,058) .{ }^{13}$ These are sometimes referred to as control groups 2, 3 and 4 below. Although each of these comparisons is informative, we focus on specifications using control group 1 because labor market behavior of mothers with older children is likely to be more similar to that of mothers of infants than those of women with no children or men. Control group 4 is potentially useful but could introduce biases due to the effects of omitted time-varying state-specific confounding factors.

Our main analysis is of the use of maternity leave. By construction, almost all individuals in control groups 1,2, and 3 have a zero value for this outcome, as they do not have newly-born children. ${ }^{14} \mathrm{We}$ also present results using a broader measure of leave-taking that adds in "other types of leave", which includes work absences due to vacation/personal days, child care problems, other family/personal obligations, or other reasons. This is of potential interest because mothers may use accrued vacation and sick leave (or related sources) as a way to take time off work to care for infants (Han et al., 2009). In addition, we provide results for these other

\footnotetext{
${ }^{13}$ In all cases, we further require the control groups to have some usual work hours during the previous year.

${ }^{14}$ A very small fraction of these control groups may be pregnant at the time of the survey (which we do not observe) and so report being absent from work for maternity leave taken before the future child is born.
} 
types of leave alone as an informal placebo test, since California's PFL policy should have no or much weaker effects on these sources of work absences than on the use of maternity leave.

We also study medium-term labor market outcomes of mothers, defined as those for women with one- to three-year-old children. Specifically, we analyze: whether the mother worked any hours during the last week, log hours worked last week, whether she worked any usual hours during the last year, log usual hours last year, and the log wage income last year. The outcomes related to employment last week indicate the mothers' most current labor market status; employment and wage income during the previous year measure labor market behavior over a longer period of time.

This analysis of medium-term outcomes introduces additional complexity because our data cover only the survey reference week and previous year (i.e. the week and year before the March CPS survey), whereas the births took place prior to that. One issue is that mothers may have had additional children in the intervening period. For this reason, we do not classify mothers based on age of the youngest child, because doing so would implicitly condition on no subsequent births and introduce potential sample selection bias. Instead, we include information on the ages of other children in the household, obtained using the family interrelationship structure of the March CPS, as additional regressors, and assign California mothers of children aged 1,2, and 3 years old to separate treatment groups, as detailed below. Second, we do not know the month of birth and so are not sure whether some children are born before or after the implementation of PFL. Therefore, when examining mothers with 1-year-old children, we classify survey years 2006-2010 as the post-treatment period and delete survey year 2005 from the analysis (since we do not know whether 1-year-olds in 2005 were born before or after PFL implementation). Similarly, for mothers of 2-year-olds, 2007-2010 constitutes the post-treatment 
period and 2006 data are dropped (2-year-olds in 2005 were born prior to PFL), while for mothers of 3-year-olds, 2008-2010 is the post-treatment period and the 2007 data are excluded.

Table 1 presents summary statistics for our preferred leave-taking analysis sample, consisting of the treatment group and control group 1 (mothers employed in the previous year with youngest children aged 5 and over). All statistics are weighted by CPS person weights. About $1 \%$ of women report using maternity leave in the reference week. This low rate of use is expected since the control group almost never takes maternity leave and, even in the treatment group, its use is generally limited to the period immediately after childbirth. Nearly $3 \%$ of women are absent from work in the reference week for other reasons.

The remainder of the table shows results when splitting the sample into treatment and control groups, and separately by the pre- and post-PFL implementation periods (i.e. 1999-2004 versus 2005 and later). Notably, there is a substantial increase in maternity leave use for the treatment group post-2004 relative to earlier - from 5.4 to nearly $11.7 \%$-- whereas there is essentially no reported use of maternity leave by the control group in either period. There is also not much change in other types of leave-taking for either the treatment or control groups (rising from 2.8 to $3.2 \%$ for the former and 1.3 to $1.6 \%$ for the latter), although higher absolute levels of use for the treatment group suggest that these provide substitutes for formal parental leave in some cases. This overall pattern of results indicates an absence of distinguishable trends in general leave-taking during the period of analysis, while the substantial rise in maternity leavetaking for the treatment group after 2004 may reflect the implementation of PFL in California. When considering medium-term labor market outcomes, nearly half of mothers with 1-, $2-$, and 3-year-old children report working in the reference week, and nearly $60 \%$ during the last year (see Appendix Table A.1 for details). There are no substantial changes in employment on 
the extensive margin, between the pre- and post-PFL periods for any of the treatment groups, but we do see suggestive evidence of an increase in work hours in the last week and year.

\section{Empirical Methods}

We employ a standard difference-in-difference (DD) design comparing changes in leavetaking for eligible California mothers of infants, surveyed pre- and post-2004, relative to corresponding differences for comparison groups unlikely to be affected by PFL. ${ }^{15}$ Our primary econometric specification takes the form:

$$
\text { (1) } Y_{i t}=\beta_{0}+\beta_{1} * T R E A T_{i}+\beta_{2} * \operatorname{POST}_{t} * T R E A T_{i}+\gamma^{\prime} X_{i t}+\delta_{t}+\varepsilon_{i t}
$$

for individual $i$ surveyed in year $t$. $Y_{i t}$ is the outcome of interest (e.g. use of maternity leave). $T_{R E A T}$ is a dummy variable set to one for mothers with children less than 1 year old at the survey date who were employed in the previous year. $P O S T_{t}$ is an indicator equal to 1 if the individual was surveyed in 2005 or later, and 0 otherwise. $X_{i t}$ is a vector of individual characteristics including indicators for: age $(<20,20-29,30-39,40-49,50-59,60+$ years old $)$, race/ethnicity (non-Hispanic white, black, Hispanic, other), education (less than high school graduate, high school graduate, some college, college graduate), marital status (married, separated, divorced, widowed, never married), and US birth. We also control for age of the youngest child when using control groups 1 and 3, and for state fixed effects and the state-year unemployment rates when using control group $4 .{ }^{16}$ In $(1), \delta_{t}$ is a vector of year fixed effects and $\varepsilon_{i t}$ is an individual-specific error term. The regressions incorporate CPS person weights and robust standard errors are reported. ${ }^{17}$ The key coefficient $\hat{\beta}_{2}$, measures the DD estimate of the effect of PFL on the treatment group.

\footnotetext{
${ }^{15}$ Since we do not observe the child's month of birth, we treat mothers with children aged $<1$ year surveyed in 2005 or later as being exposed to PFL, and treat survey years 1999-2004 as the pre-treatment period.

${ }^{16} \mathrm{POST}_{\mathrm{t}}$ is omitted from this model because it is collinear with the year fixed effects.

${ }^{17}$ Unweighted regressions yield very similar results.
} 
We present the results obtained from linear probability (LP) models, since marginal effects on interaction terms in logit and probit models are more difficult to compute and interpret (Ai and Norton, 2003). However, prior to doing so, we estimated LP and probit models for equations corresponding to equation (1), except without the interaction term. The estimated marginal effects were very similar, suggesting that the LP estimates provide useful information.

We estimate a variant of equation (1) when examining how California's paid family leave program affects the medium-term labor market outcomes of mothers. As discussed, California mothers with children aged 1,2, and 3 years old are assigned to separate treatment groups, and California mothers whose youngest children are 7-17 years old are placed in the control group. These difference-in-difference regressions include additional controls for the exact ages of younger children in the household. ${ }^{18}$ As discussed, survey years 2006-2010 are the posttreatment period and 2005 data are dropped, when studying mothers of 1-year-olds; 2007-2010 (2008-2010) represents the post-treatment period and 2006 (2007) data are excluded when examining mothers of 2-year-olds (3-year-olds).

\section{Results}

\section{A. California's PFL Program Increases Leave-Taking}

Table 2 presents the main set of results on leave-taking, using the four alternative control groups. In each case, we find a statistically significant six to seven percentage point increase in the likelihood of maternity leave-taking for the treatment group following PFL implementation (column 1). The estimated effect is virtually identical for the broader definition of leave, which adds in other forms of time off work (column 2). Conversely, the estimated impacts for leavetaking other than maternity leave are miniscule and statistically insignificant (column 3),

\footnotetext{
${ }^{18}$ For instance, when women with 3 -year-olds constitute the treatment group, we include indicators for children $<1$, 1 and 2 years old (three variables).
} 
providing evidence that the results are not due to spurious changes in leave-taking among the treatment group.

Magnitudes of the estimated effects are quite large. Pre-program maternity leave-taking for the treatment group averages 5.4\%. Relative to this baseline, our estimates suggest that PFL increased leave use by 115 to nearly $140 \%$, depending on the choice of control groups. Such substantial effects seem reasonable since eligibility for California PFL is much wider than for other programs and, particularly, contrasts with the firm size, work history and other exclusions limiting eligibility under the FMLA. Moreover, some workers who cannot afford to take unpaid time off work may be able to do so when receiving partial wage replacement.

It is also informative to interpret these results in terms of effects on the length of maternity leaves taken. We do not measure such durations directly but instead know whether women with infants are on leave during the reference week. Under reasonable assumptions, we can infer from this the percentage of weeks that such mothers use leave during their child's first year of life. Specifically, if they were on maternity leave $5.4 \%$ of the weeks during the preprogram period, this corresponds to an average leave duration of 2.8 weeks (52 weeks $\times$ 0.054/week). The findings above indicate that PFL increased leave-taking by 6.1 to 7.4 percentage points, corresponding to an additional 3.2 to 3.8 weeks of leave, and implying that these mothers used between one-half and three-fifths of the paid leave made newly available to them.

The DD estimates could be biased if the "effects" of PFL are actually due to unobserved factors affecting the treatment group differently than the control groups, or if they affect other types of leave-taking in addition to maternity leave. We have already addressed the second of these concerns, through our placebo tests on other types of leave. To examine the first 
possibility, we conducted an additional falsification test by estimating DD specifications for other states with temporary disability insurance program - Hawaii, New York, and Rhode Island - but that did not implement paid family leave policies during the analysis period. ${ }^{19}$ Since other TDI states offer some (although more limited than California) paid leave, it seems likely that we would see qualitatively similar, although presumably smaller, estimated effects for these states if the California results are due to unobserved correlates of paid leave-taking. By contrast, if PFL is causing leave-taking to increase, we would not expect to see any effects for the other TDI states.

The results of this falsification test are summarized in Table 3. Across all four control groups, we see only small (two to three percentage point) and statistically insignificant effects of the placebo PFL treatment post-2004. ${ }^{20}$ This raises the possibility that our previous estimates slightly overstate the effects of California's PFL program. However, the overall findings do not change - for instance, even a three percentage point reduction due to unobserved confounding factors would imply a 3.1 to 4.4 percentage point rise in leave-taking, corresponding to a 57 to $82 \%$ increase or an additional 1.6 to 2.3 weeks of leave.

Finally, we tested the robustness of our main results to two additional alternative specifications. In the first, we varied the minimum child age threshold for women in the control group, estimating specifications where control group 1 was successively modified to include mothers with youngest children aged $2-17,3-17,4-17,5-17,6-17,7-17$, or 8-17. In all cases, PFL program was associated with a statistically significant 6.2 to 6.4 percentage point increase in leave-taking. Second, to examine whether leave-taking in California might have been influenced

\footnotetext{
${ }^{19}$ Specifically, the treatment group consists of women with infants who were employed in the previous year and resided in Hawaii, New York, and Rhode Island. Control groups 1, 2, and 3 consider the same populations as before (in these states). The one change is that since New York is a TDI state, control group 4 now consists of women with a youngest child <1 year old in Florida, Pennsylvania, and Texas (large non-TDI states). The other TDI state, New Jersey, implemented a paid family leave policy in 2008 and so is excluded from this analysis.

${ }^{20}$ Conversely, main effects on leave-taking for the treatment group are large and statistically significant.
} 
by pre-existing differential trends between the treatment and control groups, we added to the basic model, interactions between the treatment group dummy variable and indicators for time periods 1-2 years and 3-4 years prior to PFL implementation (i.e. for 2002-2003 and 2000-2001 respectively). If there were differential trends, we would expect the coefficients on these interactions to be large and significant. Instead, they were always small (-1 to 0.5 percentage points) and insignificant, and their inclusion did not materially affect the estimated posttreatment PFL effect.

\section{B. California's PFL Program Reduces Disparities in Leave-Taking}

We next investigate whether California's PFL program had heterogeneous effects on the leave-taking of women with infants, using our preferred specification, where the control group consists of employed (in the previous year) women whose youngest children are aged 5-17. As mentioned, past research suggests that unpaid maternity leave primarily benefits relatively advantaged (e.g. college-educated and married) mothers and so it is interesting to examine whether paid time off work makes leave-taking more accessible to disadvantaged mothers.

Tables 4 and 5 present difference-in-difference estimates of the effects of PFL on leavetaking for subgroups of women stratified by education (high school degree or less, some college, college or more), marital status, and race/ethnicity (non-Hispanic white, black, Hispanic). We present the pre- and post-period means (descriptive statistics) for the treatment and control groups, as well as the simple pre versus post and treatment versus control differences and the

corresponding differences-in-differences (in bold), again without other controls. Finally, in each panel, the bottom rows and right-most columns present regression-adjusted differences, from models that include all of the demographic controls; the (bolded) regression-adjusted difference- 
in-difference estimate comes from the key interaction coefficient in equation (1), estimated for each subgroup. $^{21}$

Differences in baseline leave-taking across demographic groups are striking. For example, in the pre-program period (1999-2004), only $2 \%$ of non-college educated treatment group mothers employed reported being on maternity leave during the reference week; this contrasts with over $9 \%$ of corresponding mothers with a college degree or more. Just $2 \%$ of unmarried treatment group mothers were on maternity leave, versus $6 \%$ of their married counterparts, and only $2 \%$ of such black mothers, as opposed to $7 \%$ of non-Hispanic whites.

Although rights to paid parental leave increased its use among all groups of mothers, both the relative and absolute magnitudes of the effects are larger for the disadvantaged. For example, leave-taking among new mothers with a high school degree and some college rose 5.3 and 7.8 percentage points, respectively, compared to a statistically insignificant 4 points for mothers with a college degree (see Table 4). Leave-taking grew 7.3 percentage points for unmarried mothers, versus 6.0 points for their married counterparts. The increases are estimated to be 11.8 and 6.0 percentage points among black and Hispanic mothers, as compared to a statistically insignificant 4.4 points among non-Hispanic whites. Similar patterns are obtained using the broader definition of leave (see Table 5). ${ }^{22}$

The growth in leave-taking was even larger for disadvantaged versus advantaged new mothers, when measured in relative terms, given their lower rates of baseline usage. For instance, the use of maternity leave increased over threefold for non-college educated mothers with infants (from 2.4 to $7.7 \%$ ), nearly fivefold for those who were unmarried (from 1.9 to $9.3 \%$ ), and

\footnotetext{
${ }^{21}$ We omit appropriate controls for each subgroup specification. For example, race covariates are omitted when we estimate regressions separately by race. The single treatment-control regression-adjusted differences also include year fixed effects.

${ }^{22}$ The tables also show that the control group saw essentially no change in maternity leave-taking or in the broader measure of leave use,
} 
sevenfold for blacks (from 2.0 to $13.7 \%$ ). ${ }^{23}$ These results imply that non-college educated, unmarried and black treatment group mothers increased average time on leave from around 1 week to about 4, 5, and 7 weeks, respectively. By contrast, college-educated, married, and nonHispanic white mothers were predicted to use 6 to 7 weeks of paid leave after implementation of California's PFL program, versus 5, 3, and 4 weeks before it. The California paid leave program thus substantially reduced previous disparities in leave-taking.

\section{Medium-Term Effects on Maternal Labor Market Outcomes}

We explore the medium-term effects of California PFL on labor market outcomes specifically looking at mothers whose children are aged 1,2, or 3 . Two restrictions limit the scope of this investigation. First, the March CPS data do not permit us to directly identify women affected by the program, because we do not observe whether these mothers were employed around the time of childbirth. Second, the recent implementation of the program implies that the post-treatment period is short.

Table 6 summarizes the results. As expected, given the relatively small number of posttreatment years and our inability to identify employment in the birth year, many of the estimates are imprecise. The most consistent finding is that paid leave rights are estimated to raise reference week work hours by a statistically significant 6 to $9 \%$, conditional on being employed (the estimate is statistically significant at the 5\% level for mothers of 1- and 3-year-olds, and marginally significant at the $10 \%$ level for mothers of 2-year-olds). This corresponds to 2 to 3 additional hours of work, from the pre-PFL baseline average of around 35 hours. We also see marginally significant 5 to $6 \%$ increases in usual weekly work hours during in the previous year. California PFL is also associated with a (statistically insignificant) increase in wage income

\footnotetext{
${ }^{23}$ These estimates are calculated by adding to the predicted treatment group pre-program levels of leave-taking (from the first column of the table) the regression-adjusted DD estimate (the last cell in each panel).
} 
during the previous year consistent with what we would expect given the increase in work hours, although lack of precision implies that these estimates should be interpreted with caution. There is no evidence that the availability of paid family leave affected subsequent employment probabilities, and small sample sizes imply that we do not have the statistical power to test for differences across subgroups of mothers.

\section{Discussion}

An important objective of government-provided entitlements to parental leave is to allow parents (particularly mothers) to have more time at home following the birth of a child. Yet there is a good deal of evidence that rights to largely unpaid leave in the United States have had only limited success in accomplishing this goal. For example, Han et al. (2008) find that two-thirds of women giving birth in 2001 and employed during pregnancy, returned to work within three months after birth. Laughlin (2011) shows that $43 \%$ of women becoming first-time mothers between 2006 and 2008, and who worked until the last month before delivery, had returned to jobs within one month after childbirth. ${ }^{24}$ Our analysis suggests that new mothers in California typically only took around 3 weeks of maternity leave, prior to the availability of PFL.

This limited leave-taking probably results, at least in part, from restrictions on the eligibility for job-protected leave under the Family and Medical Leave Act and, even for those who qualify, difficulties in financing unpaid time off work. The latter issue is particularly salient for disadvantaged mothers, who generally earn less and have fewer financial resources. The provision of payment during the leave period may help to ameliorate these difficulties, thereby both raising overall leave-taking and reducing disparities in its use.

\footnotetext{
${ }^{24}$ Moreover, Laughlin (2011) indicates that $26 \%$ of women employed during pregnancy either quit or were let go from their jobs, implying that even this relatively rapid return to work overstates the use of maternity leave.
} 
Our study of California's first in the nation paid family leave program verifies both possibilities. We show that the overall use of maternity (but not paternity) leave increased by an average of 3 to 4 weeks, after the program was enacted, with especially large growth occurring for non-college educated, unmarried, and nonwhite mothers. These groups typically used only around 1 week of leave, prior to the enactment of PFL, compared to between 3 and 5 weeks for their advantaged counterparts. After rights to paid leave were provided, however, high school educated, unmarried, and black mothers took 4,5 , and 7 weeks of leave, respectively, approaching the estimated 6 to 7 weeks used by their more advantaged peers.

Parental leave entitlements may also either help or damage the longer-run labor market outcomes of women. For instance, they may provide benefits by increasing job continuity, and thereby preserving job-specific human capital, or be harmful, if they cause employers to restrict the jobs available to women. Our exploratory analysis of medium-term outcomes fails to uncover any negative effects but instead provides suggestive evidence of 6 to $9 \%$ increases in work hours, conditional on employment, 1 to 3 years after the birth, and possibly with similar growth in wage income.

Our analysis indicates that California's PFL program achieved the first-order objective of increasing leave-taking among new mothers, particularly those who are disadvantaged. Moreover, it probably did not damage their medium-term labor market outcomes and may have yielded some benefits. It would next be of interest to understand the impacts for longer-term outcomes for both mothers and their children. In regard to the latter, prior research finds that maternity leave extends durations of breast-feeding, but with mixed evidence on the impact for children's future health and development (Ruhm and Waldfogel, in press). Even with California PFL, the time mothers spend at home with newborns remains relatively short, in comparison to 
leaves taken in Canada and European countries. That said, leave-taking during the first weeks and months of a child's life may be particularly beneficial, so, it will be of great interest to examine longer-term effects for health and development, as the children afforded coverage by California's PFL grow older, and data on such outcomes become available. 


\section{References}

Ai, Chunrong and Edward C. Norton. 2003. "Interaction Terms in Logit and Probit Models," Economics Letters 80: 123-129.

Applebaum, Eileen and Ruth Milkman. 2011. Leaves that Pay: Employer and Worker Experiences with Paid Family Leave in California, Center for Economic and Policy Research, accessed at http://www.cepr.net/documents/publications/paid-family-leave-12011.pdf.

Baker, Michael and Milligan, Kevin. 2008. "Maternal employment, breastfeeding, and health: Evidence from maternity leave mandates." Journal of Health Economics 27(4): 871-887.

Burgess, Simon, Paul Gregg, Carol Propper and Elizabeth Washbrook. 2008. "Maternity Rights and Mothers' Return to Work" Labour Economics 15(2): 168-201.

Carneiro, Pedro, Løken, Katrine, and Salvanes, Kjell. 2010. “A Flying Start? Long-Term Consequences of Maternal Time Investments in Children During Their First Year of Life." IZA Discussion Paper No. 5362.

Doucet, Andrea, Donna S. Lero, and Diane-Gabrielle Tremblay. 2011. "Canada" in Peter Moss, ed. International Review of Leave Policies and Related Research, 2011, Institution of Education, University of London, accessed at http://www.leavenetwork.org/fileadmin/Leavenetwork/Annual_reviews/Complete_review_2 011.pdf.

Dustmann, Christian and Uta Schönberg. 2008. "The Effects of Expansions in Maternity Leave Coverage on Children's Long-Term Outcomes” IZA Discussion Paper No. 3605, July.

Earle, Alison, Zitha Mokomane, and Jody Heymann. 2011. "International Perspectives on WorkFamily Policies." Future of Children 21(2): 191-210. 
Fass, Sarah. 2009. Paid Leave in the States: A Critical Support for Low-Wage Workers and Their Families. Mailman School of Public Health, Columbia University, accessed at http://www.nccp.org/publications/pdf/text_864.pdf.

Gregg, Paul, Maria Gutierrez-Domenech, and Jane Waldfogel. 2007. "The Employment of Married Mothers in Great Britain: 1974-2000.” Economica 74(296): 842-864.

Han, Wen-Jui, Christopher J. Ruhm and Jane Waldfogel. 2009. "Parental Leave Policies and Parents' Employment and Leave-Taking.” Journal of Policy Analysis and Management 28(1): $29-54$.

Han, Wen-Jui, Christopher J. Ruhm, Jane Waldfogel and Elizabeth Washbrook. 2008. “The Timing of Mothers' Employment After Childbirth.” Monthly Labor Review 131(6): 15-27.

Han, Wen-Jui and Jane Waldfogel. 2003. "Parental Leave: The Impact of Recent Legislation on Parents’ Leave-Taking.” Demography 40(1): 191-200.

Jaumotte, Florence. 2004. "Labour Force Participation of Women: Empirical Evidence on the Role of Policy and Other Determinants in OECD Countries.” OECD Economic Studies No. 37 .

King, Miriam, Steven Ruggles, J. Trent Alexander, Sarah Flood, Katie Genadek, Matthew B. Schroeder, Brandon Trampe, and Rebecca Vick. 2010. Integrated Public Use Microdata Series, Current Population Survey: Version 3.0. [Machine-readable database]. Minneapolis: University of Minnesota.

Klerman, Jacob and Leibowitz, Arleen. 1997. “Labor Supply Effects of State Maternity Leave Legislation.” In Francine Blau and Ronald Ehrenberg (eds.). Gender and Family Issues in the Workplace (pp.65-85). New York: Russell Sage Foundation. 
Laughlin, Lynda. 2011. "Maternity Leave and Employment Patterns: 2006-2008." Current Population Report, P70-128, U.S. Census Bureau, Washington, DC.

Liu, Qian and Skans, Oskar Nordstrom. 2010. "The Duration of Paid Parental Leave and Children's Scholastic Performance.” B.E. Journal of Economic Analysis and Policy 10(1): Article 3.

Pettit, Becky and Hook, Jennifer. 2005. “The Structure of Women's Employment in Comparative Perspective.” Social Forces 84(2): 779-801.

Rasmussen, Astrid Wurtz. 2010. “Increasing the Length of Parents' Birth-Related Leave: The Effect on Children's Long-Term Educational Outcomes." Labour Economics 17: 91-100.

Rønsen, Marit and Marianne Sundström. 1996. "Maternal Employment in Scandinavia: A Comparison of the After-Birth Employment Activity of Norwegian and Swedish Women" Journal of Population Economics 9(3): 267-285.

Ruhm, Christopher J. 1998. “The Economic Consequences of Parental Leave Mandates: Lessons from Europe.” Quarterly Journal of Economics 113(1): 285-317.

Ruhm, Christopher J. 2011. "Policies to Assist Parents with Young Children" The Future of Children 21(2): 37-68.

Ruhm, Christopher J. and Jane Waldfogel. In press. "Long-Term Effects of Early Childhood Care and Education." Nordic Economic Policy Review.

U.S. Department of Labor. 2010. "Fact Sheet \#28: The Family and Medical Leave Act of 1993", accessed at http://www.dol.gov/whd/regs/compliance/whdfs28.htm.

Waldfogel, Jane. 1999. "The Impact of the Family and Medical Leave Act." Journal of Policy Analysis and Management 18(2): 281-302. 
Washbrook, Elizabeth, Ruhm, Christopher, Waldfogel, Jane, and Han, Wen-Jui. 2011. "Public Policies, Women's Employment after Childbirth, and Child Well-Being." B.E. Journal of Economic Analysis and Policy 11(1): Article 43. 
Table 1: Descriptive Statistics for Selected Analysis Variables

\begin{tabular}{|c|c|c|c|c|c|c|c|c|c|c|}
\hline & \multirow{2}{*}{\multicolumn{2}{|c|}{$\begin{array}{l}\text { ANALYSIS } \\
\text { SAMPLE } \\
\mathrm{N}=\mathbf{1 4 , 9 7 7} \\
\end{array}$}} & \multicolumn{4}{|c|}{$\begin{array}{c}\text { TREATMENT: MOTHERS OF } \\
\text { YOUNGEST CHILDREN AGED <1 IN } \\
\text { CA WHO WORKED ANY HOURS } \\
\text { LAST YEAR }\end{array}$} & \multicolumn{4}{|c|}{$\begin{array}{l}\text { CONTROL 1: MOTHERS OF } \\
\text { YOUNGEST CHILDREN AGED 5-17 IN } \\
\text { CA WHO WORKED ANY HOURS } \\
\text { LAST YEAR }\end{array}$} \\
\hline & & & Pre (1) & $=649)$ & Post ( & $=773)$ & Pre $(\mathrm{N}=$ & $6,097)$ & Post (N & $7,458)$ \\
\hline & Mean & SD & Mean & SD & Mean & SD & Mean & SD & Mean & SD \\
\hline Age of Youngest Child ( 0 means $<1$ ) & 9.607 & 4.827 & 0.000 & 0.000 & 0.000 & 0.000 & 10.547 & 3.684 & 10.914 & 3.782 \\
\hline Mother's Age: $<20$ & 0.004 & 0.062 & 0.033 & 0.179 & 0.024 & 0.155 & 0.001 & 0.037 & 0.000 & 0.021 \\
\hline Mother's Age: 20-29 & 0.097 & 0.296 & 0.443 & 0.497 & 0.417 & 0.493 & 0.062 & 0.241 & 0.054 & 0.226 \\
\hline Mother's Age: 30-39 & 0.351 & 0.477 & 0.446 & 0.497 & 0.503 & 0.500 & 0.364 & 0.481 & 0.309 & 0.462 \\
\hline Mother's Age: 40-49 & 0.440 & 0.496 & 0.077 & 0.268 & 0.049 & 0.216 & 0.477 & 0.500 & 0.492 & 0.500 \\
\hline Mother's Age: 50-59 & 0.103 & 0.304 & 0.000 & 0.000 & 0.001 & 0.029 & 0.092 & 0.289 & 0.137 & 0.344 \\
\hline Mother is Non-Hispanic White & 0.429 & 0.495 & 0.446 & 0.497 & 0.419 & 0.494 & 0.456 & 0.498 & 0.401 & 0.490 \\
\hline Mother is Black & 0.074 & 0.261 & 0.058 & 0.235 & 0.063 & 0.244 & 0.075 & 0.264 & 0.075 & 0.264 \\
\hline Mother is Hispanic & 0.352 & 0.478 & 0.342 & 0.475 & 0.372 & 0.484 & 0.326 & 0.469 & 0.378 & 0.485 \\
\hline Mother is Other Race & 0.164 & 0.370 & 0.168 & 0.374 & 0.174 & 0.379 & 0.156 & 0.363 & 0.171 & 0.376 \\
\hline Mother is Married & 0.724 & 0.447 & 0.803 & 0.398 & 0.808 & 0.394 & 0.714 & 0.452 & 0.716 & 0.451 \\
\hline Mother is Separated & 0.049 & 0.217 & 0.027 & 0.162 & 0.021 & 0.143 & 0.051 & 0.220 & 0.053 & 0.225 \\
\hline Mother is Divorced & 0.117 & 0.322 & 0.022 & 0.146 & 0.017 & 0.130 & 0.136 & 0.343 & 0.122 & 0.327 \\
\hline Mother is Widowed & 0.015 & 0.122 & 0.000 & 0.000 & 0.001 & 0.031 & 0.018 & 0.134 & 0.015 & 0.122 \\
\hline Mother Born in US & 0.611 & 0.488 & 0.683 & 0.466 & 0.689 & 0.463 & 0.625 & 0.484 & 0.579 & 0.494 \\
\hline Mother's Ed: <HS & 0.170 & 0.376 & 0.141 & 0.348 & 0.129 & 0.335 & 0.174 & 0.379 & 0.175 & 0.380 \\
\hline Mother's Ed: HS Degree & 0.226 & 0.418 & 0.243 & 0.429 & 0.167 & 0.373 & 0.243 & 0.429 & 0.214 & 0.410 \\
\hline Mother's Ed: Some College & 0.315 & 0.465 & 0.308 & 0.462 & 0.300 & 0.459 & 0.328 & 0.470 & 0.304 & 0.460 \\
\hline Mother's Ed: College+ & 0.289 & 0.453 & 0.308 & 0.462 & 0.404 & 0.491 & 0.255 & 0.436 & 0.307 & 0.461 \\
\hline $\begin{array}{l}\text { Absent from Job for Maternity Leave } \\
\text { Absent from Job for Maternity Leave and }\end{array}$ & 0.010 & 0.101 & 0.054 & 0.227 & 0.117 & 0.322 & 0.002 & 0.041 & 0.001 & 0.030 \\
\hline $\begin{array}{l}\text { Other Types of Leave }{ }^{1} \\
\text { Absent from Job for Other Types of Leave }\end{array}$ & 0.027 & 0.161 & 0.082 & 0.274 & 0.149 & 0.357 & 0.015 & 0.122 & 0.017 & 0.129 \\
\hline (Only) & 0.016 & 0.127 & 0.028 & 0.164 & 0.032 & 0.177 & 0.013 & 0.115 & 0.016 & 0.126 \\
\hline
\end{tabular}

Notes: The data come from the 1999-2010 March CPS surveys.

${ }^{1}$ This includes being absent from work in the last week due to for vacation/personal days, child care problems, other family/personal obligations, maternity/paternity leave, or other reasons.

All statistics are weighted by the March CPS Supplement person weights. 
Table 2: Effects of CA Paid Family Leave on Leave-Taking Among Employed Women

\begin{tabular}{|c|c|c|c|}
\hline Outcomes: & Maternity Leave & Broad Leave Definition $^{1}$ & Other Types of Leave ${ }^{2}$ \\
\hline \multicolumn{4}{|c|}{ Control Group 1: Mothers of Youngest Children Aged 5-17 Who Worked Any Hours Last Year (N=14,977) } \\
\hline \multirow[t]{2}{*}{ Treatment Group } & $0.0541 * * *$ & $0.0786 * * *$ & $0.0246 * *$ \\
\hline & (0.0099) & $(0.0127)$ & $(0.0084)$ \\
\hline \multirow[t]{2}{*}{ Treatment * Post 2004} & $0.0622 * * *$ & $0.0632 * * *$ & 0.0010 \\
\hline & $(0.0161)$ & $(0.0186)$ & $(0.0102)$ \\
\hline \multicolumn{4}{|c|}{ Control Group 2: Women With No Children Who Worked Any Hours Last Year $(\mathrm{N}=23,513)$} \\
\hline \multirow[t]{2}{*}{ Treatment Group } & $0.0489 * * *$ & $0.0608 * * *$ & 0.0119 \\
\hline & $(0.0095)$ & $(0.0118)$ & $(0.0074)$ \\
\hline \multirow[t]{2}{*}{ Treatment * Post 2004} & $0.0613 * * *$ & $0.0655^{* * *}$ & 0.0042 \\
\hline & $(0.0161)$ & $(0.0186)$ & $(0.0102)$ \\
\hline \multicolumn{4}{|c|}{ Control Group 3: Men With No Children Aged <1 Year Who Worked Any Hours Last Year $(\mathrm{N}=55,006)$} \\
\hline \multirow[t]{2}{*}{ Treatment Group } & $0.0543^{* * *}$ & $0.0824 * * *$ & $0.0281 * * *$ \\
\hline & (0.0094) & $(0.0119)$ & $(0.0076)$ \\
\hline \multirow[t]{2}{*}{ Treatment * Post 2004} & $0.0625 * * *$ & $0.0666 * * *$ & 0.0041 \\
\hline & $(0.0161)$ & $(0.0185)$ & $(0.0101)$ \\
\hline \multicolumn{4}{|c|}{ Control Group 4: Mothers of Youngest Child <1 Year in FL, NY, TX Who Worked Any Hours Last Year $(\mathrm{N}=3,480)$} \\
\hline Treatment Group & -- & -- & -- \\
\hline \multirow[t]{2}{*}{ Treatment * Post 2004} & $0.0737^{* *}$ & $0.0705^{* *}$ & -0.0032 \\
\hline & $(0.0234)$ & $(0.0261)$ & $(0.0130)$ \\
\hline
\end{tabular}

Notes: Each column in each panel is from a separate regression. The data come from the 1999-2010 March CPS surveys. The treatment group consists of women with a youngest child aged $<1$ year in the household who reported working any hours last year and who reside in California. All regressions include controls for age categories (<20, 20-29, 30-39, 40-49, 50-59, 60+), indicators for race/ethnicity (non-Hispanic white, black, Hispanic, other), indicators for marital status (married, divorced, separated, widowed, never-married), an indicator for being born in the US, and indicators for education categories (<HS, HS, some college, college + ). All regressions include dummies for the year of the survey. The regressions in the 1st and 3rd panels (Control Groups 1 and 3) also include indicators for single years of youngest child's age.The regressions in the 4th panel (Control Group 4) include state fixed effects and state-year unemployment rates. Standard errors are robust to heterogeneity.

${ }^{1}$ This outcome is an indicator for being with a job but absent from work in the last week due to for vacation/personal days, child care problems, other family/personal obligations, maternity/paternity leave, or other reasons.

${ }^{2}$ This outcome is an indicator for being with a job but absent from work in the last week due to for vacation/personal days, child care problems, other family/personal obligations, or other reasons (NOT including maternity/paternity leave).

Significance levels: $+p<0.10 * * p<0.05 * * * p<0.001$. All regressions are weighted by the March CPS Supplement person weights. 
Table 3: Falsification Test - Estimates of CA Paid Family Leave on Leave-Taking in Other TDI States

\begin{tabular}{|c|c|c|c|}
\hline Outcomes: & Maternity Leave & Broad Leave Definition $^{1}$ & Other Types of Leave ${ }^{2}$ \\
\hline \multicolumn{4}{|c|}{ Control Group 1: Mothers of Youngest Children Aged 5-17 Who Worked Any Hours Last Year $(\mathrm{N}=13,234)$} \\
\hline \multirow[t]{2}{*}{ Treatment Group } & $0.0960^{* * *}$ & $0.0920 * * *$ & -0.0041 \\
\hline & $(0.0144)$ & $(0.0165)$ & $(0.0083)$ \\
\hline \multirow[t]{2}{*}{ Treatment * Post 2004} & 0.0261 & 0.0286 & 0.0025 \\
\hline & $(0.0241)$ & $(0.0255)$ & $(0.0097)$ \\
\hline \multicolumn{4}{|c|}{ Control Group 2: Women With No Children Who Worked Any Hours Last Year $(\mathrm{N}=21,368)$} \\
\hline \multirow[t]{2}{*}{ Treatment Group } & $0.0958^{* * *}$ & $0.0894 * * *$ & -0.0064 \\
\hline & $(0.0140)$ & $(0.0150)$ & $(0.0058)$ \\
\hline \multirow[t]{2}{*}{ Treatment * Post 2004} & 0.0261 & 0.0366 & 0.0105 \\
\hline & $(0.0241)$ & $(0.0255)$ & $(0.0097)$ \\
\hline \multicolumn{4}{|c|}{ Control Group 3: Men With No Children Aged <1 Year Who Worked Any Hours Last Year $(\mathrm{N}=44,075)$} \\
\hline \multirow[t]{2}{*}{ Treatment Group } & 0.0996*** & $0.1214^{* * *}$ & $0.0217+$ \\
\hline & $(0.0140)$ & $(0.0187)$ & $(0.0127)$ \\
\hline \multirow[t]{2}{*}{ Treatment * Post 2004} & 0.0268 & 0.0337 & 0.0068 \\
\hline & $(0.0241)$ & $(0.0255)$ & $(0.0095)$ \\
\hline \multicolumn{4}{|c|}{ Control Group 4: Mothers of Youngest Child <1 Year in FL, PA, TX Who Worked Any Hours Last Year $(\mathrm{N}=3,242)$} \\
\hline Treatment Group & "-- & --- & --- \\
\hline \multirow[t]{2}{*}{ Treatment * Post 2004} & 0.0243 & 0.0199 & -0.0044 \\
\hline & $(0.0281)$ & $(0.0298)$ & $(0.0113)$ \\
\hline
\end{tabular}

\footnotetext{
Notes: Each column in each panel is from a separate regression. The data come from the 1999-2010 March CPS surveys. The placebo treatment group consists of women with a youngest child aged $<1$ year in the household who reported working any hours in the last year and who reside in Hawaii, New York, or Rhode Island (other states that offer Temporary Disability Insurance but do not offer paid maternity leave). All regressions include controls for age categories (<20, 20-29, 30-39, 40-49, 50-59, 60+), indicators for race/ethnicity (non-Hispanic white, black, Hispanic, other), indicators for marital status (married, divorced, separated, widowed, never-married), an indicator for being born in the US, indicators for education categories (<HS, HS, some college, college + ), and the state-year unemployment rate. All regressions include dummies for the year of the survey. The regressions in the 1st and 3rd panels (Control Groups 1 and 3) also include indicators for single years of youngest child's age.The regressions in the 4th panel (Control Group 4) also include state fixed effects.

${ }^{1}$ This outcome is an indicator for being with a job but absent from work in the last week due to for vacation/personal days, child care problems, other family/personal obligations, maternity/paternity leave, or other reasons.

${ }^{2}$ This outcome is an indicator for being with a job but absent from work in the last week due to for vacation/personal days, child care problems, other family/personal obligations, or other reasons (NOT including maternity/paternity leave).

Significance levels: $+p<0.10^{* *} p<0.05^{* * *} p<0.001$. All regressions are weighted by the March CPS Supplement person weights.
} 
Table 4: Subgroup Estimates of Maternity Leave Use

\begin{tabular}{|c|c|c|c|c|}
\hline \multicolumn{5}{|c|}{ WHOLE SAMPLE $(\mathrm{N}=14,977)$} \\
\hline & Treatment Group & Control Group 1 & Difference & Reg-Adjusted Difference \\
\hline Pre & 0.0542 & 0.0017 & $0.0525^{* * *}$ & $0.0487^{* * *}$ \\
\hline Post & 0.1170 & 0.0009 & $0.1161^{* * *}$ & $0.1204 * * *$ \\
\hline \multirow{2}{*}{ Difference } & $0.0628^{* * *}$ & -0.0008 & $0.0636 * * *$ & \\
\hline & & & & $0.0622 * * *$ \\
\hline Reg-Adjusted Difference & $0.0563 * * *$ & -0.0006 & & $(0.0161)$ \\
\hline \multicolumn{5}{|c|}{ MOTHERS WITH HIGH SCHOOL DEGREE OR LESS $(\mathrm{N}=6,263)$} \\
\hline & Treatment Group & Control Group 1 & Difference & Reg-Adjusted Difference \\
\hline Pre & 0.0237 & 0.0024 & $0.0213^{* *}$ & 0.0163 \\
\hline Post & 0.0764 & 0.0014 & $0.0750 * * *$ & $0.0794 * * *$ \\
\hline \multirow[t]{2}{*}{ Difference } & $0.0527^{* *}$ & -0.0010 & $0.0537 * *$ & \\
\hline & & & & $0.0529 * *$ \\
\hline Reg-Adjusted Difference & $0.0563 * *$ & -0.0010 & & $(0.0204)$ \\
\hline \multicolumn{5}{|c|}{ MOTHERS WITH SOME COLLEGE $(\mathrm{N}=4,602)$} \\
\hline & Treatment Group & Control Group 1 & Difference & Reg-Adjusted Difference \\
\hline Pre & 0.0524 & 0.0014 & $0.0510^{* *}$ & $0.0482^{* *}$ \\
\hline Post & 0.1303 & 0.0007 & $0.1297 * * *$ & $0.1380^{* * *}$ \\
\hline \multirow[t]{2}{*}{ Difference } & $0.0779 * *$ & -0.0007 & $0.0786^{* *}$ & \\
\hline & & & & $0.0784 * *$ \\
\hline Reg-Adjusted Difference & $0.0745^{* *}$ & -0.0004 & & $(0.0303)$ \\
\hline \multicolumn{5}{|c|}{ MOTHERS WITH COLLEGE DEGREE OR MORE $(\mathrm{N}=4,112)$} \\
\hline & Treatment Group & Control Group 1 & Difference & Reg-Adjusted Difference \\
\hline Pre & 0.0941 & 0.0010 & $0.0931^{* * *}$ & $0.0814^{* * *}$ \\
\hline Post & 0.1368 & 0.0004 & $0.1364 * * *$ & $0.1378^{* * *}$ \\
\hline \multirow[t]{2}{*}{ Difference } & 0.0428 & -0.0006 & 0.0434 & \\
\hline & & & & 0.0424 \\
\hline Reg-Adjusted Difference & 0.0393 & -0.0005 & & $(0.0320)$ \\
\hline \multicolumn{5}{|c|}{ UNMARRIED MOTHERS $(\mathrm{N}=4,123)$} \\
\hline & Treatment Group & Control Group 1 & Difference & Reg-Adjusted Difference \\
\hline Pre & 0.0192 & 0.0017 & 0.0176 & 0.0154 \\
\hline Post & 0.0942 & 0.0019 & $0.0923 * * *$ & $0.0970 * * *$ \\
\hline \multirow[t]{2}{*}{ Difference } & $0.0750 * *$ & 0.0003 & $0.0747^{* *}$ & \\
\hline & & & & $0.0736 * *$ \\
\hline Reg-Adjusted Difference & $0.0704 * *$ & 0.0005 & & $(0.0281)$ \\
\hline \multicolumn{5}{|c|}{ MARRIED MOTHERS $(\mathrm{N}=10,854)$} \\
\hline & Treatment Group & Control Group 1 & Difference & Reg-Adjusted Difference \\
\hline$\overline{P r e}$ & 0.0628 & 0.0017 & $0.0611^{* * *}$ & $0.0542^{* * *}$ \\
\hline Post & 0.1224 & 0.0005 & $0.1219 * * *$ & $0.1246^{* * *}$ \\
\hline \multirow[t]{2}{*}{ Difference } & $0.0596 * *$ & $-0.0013+$ & $0.0609 * *$ & \\
\hline & & & & $0.0597^{* *}$ \\
\hline Reg-Adjusted Difference & $0.0525 * *$ & -0.0010 & & $(0.0187)$ \\
\hline \multicolumn{5}{|c|}{$\begin{array}{l}\text { NON-HISPANIC WHITE MOTHERS ( } \mathrm{N}=5,890) \\
\end{array}$} \\
\hline & Treatment Group & Control Group 1 & Difference & Reg-Adjusted Difference \\
\hline Pre & 0.0706 & 0.0011 & $0.0694 * * *$ & $0.0640^{* * *}$ \\
\hline Post & 0.1165 & 0.0005 & $0.1160 * * *$ & $0.1256^{* * *}$ \\
\hline \multirow[t]{2}{*}{ Difference } & $0.0459+$ & -0.0006 & $0.0466+$ & \\
\hline & & & & 0.0437 \\
\hline Reg-Adjusted Difference & 0.0297 & -0.0005 & & $(0.0271)$ \\
\hline \multicolumn{5}{|l|}{ BLACK MOTHERS ( $\mathrm{N}=950)$} \\
\hline & Treatment Group & Control Group 1 & Difference & Reg-Adjusted Difference \\
\hline$\overline{\text { Pre }}$ & 0.0195 & 0.0024 & 0.0171 & 0.0058 \\
\hline Post & 0.1365 & 0.0000 & $0.1365^{* *}$ & $0.1651^{* *}$ \\
\hline Difference & $0.1170+$ & -0.0024 & $0.1194 * *$ & \\
\hline & & & & $0.1176 * *$ \\
\hline Reg-Adjusted Difference & $0.1206 * *$ & -0.0020 & & $(0.0571)$ \\
\hline HISPANIC MOTHERS ( $\mathrm{N}=6$ & & & & \\
\hline & Treatment Group & Control Group 1 & Difference & Reg-Adjusted Difference \\
\hline Pre & 0.03898 & 0.00250 & $0.0365^{* *}$ & $0.0356^{* *}$ \\
\hline Post & 0.09901 & 0.00149 & $0.0975^{* * *}$ & $0.0913^{* * *}$ \\
\hline Difference & $0.0600 * *$ & -0.0010 & $0.0610 * *$ & \\
\hline & & & & $0.0603^{* *}$ \\
\hline Reg-Adjusted Difference & $0.0554 * *$ & -0.0008 & & $(0.0214)$ \\
\hline
\end{tabular}

Notes: The data come from the 1999-2010 March CPS surveys. The treatment group consists of women with a youngest child aged $<1$ year in the household who reported working any hours last year and who reside in California. Control group 1 consists of women with a youngest child aged 5-17 years in the household who reported working any hours last year and who reside in California.

The outcome is an indicator for being absent from work last week for maternity leave. Regression-adjusted differences control for age categories

$(<20,20-29,30-39,40-49,50-59,60+)$, indicators for race/ethnicity (non-Hispanic white, black, Hispanic, other), indicators for marital status (married, divorced, separated, widowed, never-married), an indicator for being born in the US, and indicators for education categories (<HS, HS, some college, college+). The treatment-control regression-adjusted differences and the regression-adjusted differences-in-differences also include indicators for youngest child's single years of age, and dummies for the year of the survey -- appropriate controls are omitted for subgroup analysis.

Significance levels: $+p<0.10 * * p<0.05 * * * p<0.001$. All statistics are weighted by the March CPS Supplement person weights. 
Table 5: Subgroup Estimates of Broad Definition of Leave Use

\begin{tabular}{|c|c|c|c|c|}
\hline \multicolumn{5}{|l|}{ WHOLE SAMPLE $(\mathrm{N}=14,977)$} \\
\hline & Treatment Group & Control Group 1 & Difference & Reg-Adjusted Difference \\
\hline Pre & 0.0818 & 0.0150 & $0.0668^{* * *}$ & $0.0693^{* * *}$ \\
\hline Post & 0.1492 & 0.0170 & $0.1322 * * *$ & $0.1396 * * *$ \\
\hline \multirow[t]{2}{*}{ Difference } & $0.0674 * * *$ & 0.0020 & $0.0654 * * *$ & \\
\hline & & & & $0.0633 * * *$ \\
\hline Reg-Adjusted Difference & $0.0586 * *$ & 0.0024 & & $(0.0185)$ \\
\hline \multicolumn{5}{|c|}{ MOTHERS WITH HIGH SCHOOL DEGREE OR LESS $(\mathrm{N}=6,263)$} \\
\hline & Treatment Group & Control Group 1 & Difference & Reg-Adjusted Difference \\
\hline Pre & 0.0421 & 0.0133 & $0.0288^{* *}$ & 0.0183 \\
\hline Post & 0.0909 & 0.0134 & $0.0775^{* * *}$ & $0.0927 * * *$ \\
\hline \multirow[t]{2}{*}{ Difference } & $0.0487^{* *}$ & 0.0000 & $0.0487 * *$ & \\
\hline & & & & $0.0483 * *$ \\
\hline Reg-Adjusted Difference & $0.0537 * *$ & -0.0002 & & $(0.0239)$ \\
\hline \multicolumn{5}{|c|}{ MOTHERS WITH SOME COLLEGE $(\mathrm{N}=4,602)$} \\
\hline & Treatment Group & Control Group 1 & Difference & Reg-Adjusted Difference \\
\hline Pre & 0.0643 & 0.0158 & $0.0485^{* *}$ & $0.0702^{* *}$ \\
\hline Post & 0.1519 & 0.0188 & $0.1330 * * *$ & $0.1369 * * *$ \\
\hline \multirow[t]{2}{*}{ Difference } & $0.0876^{* *}$ & 0.0030 & $0.0846 * *$ & \\
\hline & & & & $0.0851 * *$ \\
\hline Reg-Adjusted Difference & $0.0892 * *$ & 0.0038 & & $(0.0327)$ \\
\hline \multicolumn{5}{|c|}{ MOTHERS WITH COLLEGE DEGREE OR MORE $(\mathrm{N}=4,112)$} \\
\hline & Treatment Group & Control Group 1 & Difference & Reg-Adjusted Difference \\
\hline Pre & 0.1489 & 0.0167 & $0.1321 * * *$ & $0.1266^{* * *}$ \\
\hline Post & 0.1900 & 0.0197 & $0.1702 * * *$ & $0.1697^{* * *}$ \\
\hline \multirow[t]{2}{*}{ Difference } & 0.0411 & 0.0030 & 0.0381 & \\
\hline & & & & 0.0356 \\
\hline Reg-Adjusted Difference & 0.0352 & 0.0039 & & $(0.0379)$ \\
\hline \multicolumn{5}{|c|}{ UNMARRIED MOTHERS $(\mathrm{N}=4,123)$} \\
\hline & Treatment Group & Control Group 1 & Difference & Reg-Adjusted Difference \\
\hline Pre & 0.0274 & 0.0149 & 0.0125 & 0.0094 \\
\hline Post & 0.1366 & 0.0137 & $0.1229 * * *$ & $0.1271 * * *$ \\
\hline \multirow[t]{2}{*}{ Difference } & $0.1092 * *$ & -0.0013 & $0.1105^{* *}$ & \\
\hline & & & & $0.1098 * *$ \\
\hline Reg-Adjusted Difference & $0.1062 * *$ & -0.0007 & & $(0.0344)$ \\
\hline \multicolumn{5}{|c|}{ MARRIED MOTHERS $(\mathrm{N}=10,854)$} \\
\hline & Treatment Group & Control Group 1 & Difference & Reg-Adjusted Difference \\
\hline Pre & 0.0952 & 0.0151 & $0.0801 * * *$ & $0.0708^{* * *}$ \\
\hline Post & 0.1522 & 0.0183 & $0.1339 * * *$ & $0.1366^{* * *}$ \\
\hline \multirow[t]{2}{*}{ Difference } & $0.0570 * *$ & 0.0033 & $0.0538 * *$ & \\
\hline & & & & $0.0515 * *$ \\
\hline Reg-Adjusted Difference & $0.0479 * *$ & 0.0038 & & $(0.0214)$ \\
\hline \multicolumn{5}{|c|}{ NON-HISPANIC WHITE MOTHERS $(\mathrm{N}=5,890)$} \\
\hline & Treatment Group & Control Group 1 & Difference & Reg-Adjusted Difference \\
\hline Pre & 0.1109 & 0.0180 & $0.0929 * * *$ & $0.0837^{* *}$ \\
\hline Post & 0.1508 & 0.0198 & $0.1310^{* * *}$ & $0.1374 * * *$ \\
\hline \multirow[t]{2}{*}{ Difference } & 0.0399 & 0.0018 & 0.0381 & \\
\hline & & & & 0.0345 \\
\hline Reg-Adjusted Difference & 0.0226 & 0.0020 & & $(0.0316)$ \\
\hline \multicolumn{5}{|l|}{ BLACK MOTHERS ( $\mathrm{N}=950)$} \\
\hline & Treatment Group & Control Group 1 & Difference & Reg-Adjusted Difference \\
\hline Pre & 0.0195 & 0.0129 & 0.0066 & 0.0150 \\
\hline Post & 0.1976 & 0.0248 & $0.1728^{* *}$ & $0.1782^{* *}$ \\
\hline Difference & $0.1781 * *$ & 0.0119 & $0.1661 * *$ & \\
\hline & & & & $0.1607 * *$ \\
\hline Reg-Adjusted Difference & $0.1880 * *$ & 0.0153 & & $(0.0687)$ \\
\hline HISPANIC MOTHERS ( $\mathrm{N}=6$ & & & & \\
\hline & Treatment Group & Control Group 1 & Difference & Reg-Adjusted Difference \\
\hline Pre & 0.0567 & 0.0124 & $0.0443 * *$ & $0.0492^{* *}$ \\
\hline Post & 0.1204 & 0.0127 & $0.1077^{* * *}$ & $0.1002^{* * *}$ \\
\hline Difference & $0.0636 * *$ & 0.0003 & $0.0634 * *$ & \\
\hline & & & & $0.0605^{* *}$ \\
\hline Reg-Adjusted Difference & $0.0552 * *$ & 0.0006 & & $(0.0238)$ \\
\hline
\end{tabular}

Notes: Please see notes under Table 5 for information about the data, the sample, and the controls.

The outcome is an indicator for being with a job but absent from work in the last week due to for vacation/personal days, child care problems, other family/personal obligations, maternity/paternity leave, or other reasons.

Significance levels: $+p<0.10^{* *} p<0.05^{* * *} p<0.001$. All statistics are weighted by the March CPS Supplement person weights. 
Table 6: Intermediate Effects of Paid Leave on Maternal Labor Market Outcomes

\begin{tabular}{|c|c|c|c|c|c|}
\hline Outcomes: & $\begin{array}{c}\text { Any Hours } \\
\text { Worked Last } \\
\text { Week }\end{array}$ & $\begin{array}{c}\text { Log Hours } \\
\text { Worked Last } \\
\text { Week }\end{array}$ & $\begin{array}{c}\text { Any Usual Hours } \\
\text { Worked Last } \\
\text { Year }\end{array}$ & $\begin{array}{c}\text { Log Usual Hours } \\
\text { Worked Last } \\
\text { Year }\end{array}$ & $\begin{array}{c}\text { Log Wage } \\
\text { Income Last } \\
\text { Year }\end{array}$ \\
\hline \multicolumn{6}{|c|}{ A. Treatment: Mothers of Children Aged 1} \\
\hline Treatment Group & $\begin{array}{c}-0.2537^{* * *} \\
(0.0241)\end{array}$ & $\begin{array}{c}-0.1520+ \\
(0.0869)\end{array}$ & $\begin{array}{c}-0.2462 * * * \\
(0.0228)\end{array}$ & $\begin{array}{l}-0.0792 \\
(0.0589)\end{array}$ & $\begin{array}{c}-0.5007^{* *} \\
(0.2073)\end{array}$ \\
\hline Treatment $* 2006+$ & $\begin{array}{l}-0.0086 \\
(0.0232)\end{array}$ & $\begin{array}{c}0.0849 * * \\
(0.0369)\end{array}$ & $\begin{array}{l}-0.0122 \\
(0.0229)\end{array}$ & $\begin{array}{c}0.0458 \\
(0.0335)\end{array}$ & $\begin{array}{c}0.0881 \\
(0.0763)\end{array}$ \\
\hline $\mathrm{N}$ & 14,512 & 9,237 & 14,512 & 10,354 & 9,634 \\
\hline B. Treatment: Moth & $\operatorname{sed} 2$ & & & & \\
\hline Treatment Group & $\begin{array}{c}-0.4303 * * * \\
(0.0313)\end{array}$ & $\begin{array}{c}-0.4505^{* * *} \\
(0.0920)\end{array}$ & $\begin{array}{c}-0.2807^{* * *} \\
(0.0334)\end{array}$ & $\begin{array}{c}-0.2294 * * * \\
(0.0524)\end{array}$ & $\begin{array}{l}-0.2050 \\
(0.5951)\end{array}$ \\
\hline Treatment $* 2007+$ & $\begin{array}{c}0.0300 \\
(0.0212)\end{array}$ & $\begin{array}{l}0.0578+ \\
(0.0347)\end{array}$ & $\begin{array}{c}0.0196 \\
(0.0208)\end{array}$ & $\begin{array}{l}0.0492+ \\
(0.0264)\end{array}$ & $\begin{array}{c}0.0179 \\
(0.0620)\end{array}$ \\
\hline $\mathrm{N}$ & 17,833 & 11,380 & 17,833 & 12,738 & 11,843 \\
\hline C. Treatment: Moth & sed 3 & & & & \\
\hline Treatment Group & $\begin{array}{c}-0.2412 * * \\
(0.0885)\end{array}$ & $\begin{array}{c}0.2435 \\
(0.3226)\end{array}$ & $\begin{array}{c}-0.2136 * * \\
(0.1003)\end{array}$ & $\begin{array}{l}-0.1295 \\
(0.1204)\end{array}$ & $\begin{array}{c}0.7515^{* *} \\
(0.3064)\end{array}$ \\
\hline Treatment $* 2008+$ & $\begin{array}{l}-0.0078 \\
(0.0234)\end{array}$ & $\begin{array}{c}0.0903 * * \\
(0.0350)\end{array}$ & $\begin{array}{c}0.0167 \\
(0.0225)\end{array}$ & $\begin{array}{l}0.0587+ \\
(0.0320)\end{array}$ & $\begin{array}{c}0.1123 \\
(0.0722)\end{array}$ \\
\hline $\mathrm{N}$ & 16,255 & 10,396 & 16,255 & 11,654 & 10,832 \\
\hline
\end{tabular}

Notes: Each column in each panel is from a separate regression. The data come from the 1999-2010 March CPS surveys. The sample of analysis includes women whose youngest children are in the household in California. The control group consists of women with a youngest child aged 717 years in the household who reside in California. Regressions in panel A are estimated on a sample omitting year 2005; regressions in panel B are estimated on a sample omitting year 2006; regressions in panel C are estimated on a sample omitting year 2007. Regressions in panel A control for whether the woman has any other children $<1$, regressions in panel B control for whether the woman has any other children aged $<1$ or 1 , and regressions in panel $\mathrm{C}$ control for whether the woman has any other children aged $<1,1$, or 2 . All regressions include controls for mother's age categories (<20, 20-29, 30-39, 40-49, 50-59, 60+), indicators for race/ethnicity (non-Hispanic white, black, Hispanic, other), indicators for marital status (married, separated, divorced, never-married), an indicator for being born in the US, indicators for education categories (<HS, HS, some college, college+), and indicators for youngest child's single years of age. All regressions include dummies for the year of the survey. Standard errors are robust to heterogeneity.

Significance levels: $+p<0.10^{* *} p<0.05^{* * *} p<0.001$. All regressions are weighted by the March CPS Supplement person weights. 


\section{Appendix Table 1: Descriptive Statistics for Labor Market Outcomes}

\begin{tabular}{|c|c|c|c|c|}
\hline & \multicolumn{2}{|c|}{ Pre } & \multicolumn{2}{|c|}{ Post } \\
\hline & Mean & SD & Mean & SD \\
\hline \multicolumn{5}{|l|}{ A. Treatment: Mothers of Children Aged $1(\mathrm{~N}=2,317)$} \\
\hline Any Hours Worked Last Week & 0.487 & 0.500 & 0.468 & 0.499 \\
\hline Number Hours Worked Last Week (No 0's) & 33.419 & 12.766 & 34.465 & 11.486 \\
\hline Log Hours Worked Last Week & 3.398 & 0.558 & 3.451 & 0.498 \\
\hline Any Usual Hours Worked Last Year & 0.583 & 0.493 & 0.536 & 0.499 \\
\hline Number Usual Hours Worked Last Year (No 0's) & 34.724 & 11.790 & 35.323 & 11.553 \\
\hline Log Usual Hours Worked Last Year & 3.449 & 0.539 & 3.481 & 0.479 \\
\hline Wage Income Last Year (2010\$) & 16014.167 & 28659.226 & 19889.409 & 43527.680 \\
\hline Log Wage Income Last Year & 9.686 & 1.281 & 9.943 & 1.279 \\
\hline \multicolumn{5}{|c|}{ B. Treatment: Mothers of Children Aged $2(\mathrm{~N}=2,900)$} \\
\hline Any Hours Worked Last Week & 0.467 & 0.499 & 0.491 & 0.500 \\
\hline Number Hours Worked Last Week (No 0's) & 34.167 & 11.563 & 34.908 & 11.883 \\
\hline Log Hours Worked Last Week & 3.436 & 0.521 & 3.450 & 0.568 \\
\hline Any Usual Hours Worked Last Year & 0.579 & 0.494 & 0.589 & 0.492 \\
\hline Number Usual Hours Worked Last Year (No 0's) & 34.771 & 11.257 & 35.296 & 10.438 \\
\hline Log Usual Hours Worked Last Year & 3.462 & 0.494 & 3.492 & 0.452 \\
\hline Wage Income Last Year (2010 \$) & 17027.669 & 31222.867 & 20891.952 & 38361.454 \\
\hline Log Wage Income Last Year & 9.814 & 1.199 & 10.012 & 1.126 \\
\hline \multicolumn{5}{|l|}{ C. Treatment: Mothers of Children Aged $3(\mathrm{~N}=2,723)$} \\
\hline Any Hours Worked Last Week & 0.493 & 0.500 & 0.483 & 0.500 \\
\hline Number Hours Worked Last Week (No O's) & 34.852 & 12.573 & 35.583 & 11.934 \\
\hline Log Hours Worked Last Week & 3.447 & 0.552 & 3.487 & 0.495 \\
\hline Any Usual Hours Worked Last Year & 0.598 & 0.490 & 0.602 & 0.490 \\
\hline Number Usual Hours Worked Last Year (No 0's) & 35.056 & 11.994 & 35.814 & 11.724 \\
\hline Log Usual Hours Worked Last Year & 3.460 & 0.529 & 3.493 & 0.513 \\
\hline Wage Income Last Year (2010 \$) & 17278.119 & 35076.466 & 20698.828 & 39853.748 \\
\hline Log Wage Income Last Year & 9.742 & 1.263 & 9.978 & 1.144 \\
\hline \multicolumn{5}{|c|}{ D. Control: Mothers of Youngest Children Aged 7+ $(\mathrm{N}=12,195)$} \\
\hline Any Hours Worked Last Week & 0.682 & 0.466 & 0.674 & 0.469 \\
\hline Number Hours Worked Last Week (No 0's) & 36.823 & 12.100 & 36.125 & 12.484 \\
\hline Log Hours Worked Last Week & 3.525 & 0.475 & 3.494 & 0.517 \\
\hline Any Usual Hours Worked Last Year & 0.766 & 0.423 & 0.739 & 0.439 \\
\hline Number Usual Hours Worked Last Year (No 0's) & 36.863 & 11.418 & 36.399 & 11.276 \\
\hline Log Usual Hours Worked Last Year & 3.535 & 0.446 & 3.520 & 0.453 \\
\hline Wage Income Last Year (2010 \$) & 25877.173 & 37379.249 & 28304.259 & 45145.483 \\
\hline Log Wage Income Last Year & 10.056 & 1.104 & 10.171 & 1.057 \\
\hline
\end{tabular}

Notes: The data come from the 1999-2010 March CPS surveys. The sample of analysis includes women whose youngest children are in the household in California. In panel A, year 2005 is omitted from the sample, and post is an indicator for years 2006 or later. In panel B, year 2006 is omitted from the sample, and post is an indicator for years 2007 or later. In panel C, year 2007 is omitted from the sample, and post is an indicator for years 2008 or later. In panel D, year 2005 is omitted from the sample, and post is an indicator for years 2006 or later. All statistics are weighted by the March CPS Supplement person weights. 